\title{
NATURWISSENSCHAFTEN
}

61. Jahrgang 1974 Heft 10, S. 456 .(C) by Springer-Verlag 1974

\section{Pleurotus-Sporen als Allergene}

\section{F. Zadražil}

Forschungsstelle von Sengbusch, Hamburg

Die Allergie durch Pleurotus ostreatus und Pleurotus florida wurde von [1] beschrieben. Im allgemeinen bekamen ca. $30-40 \%$ der Personen, die mit Pleurotus-Sporen in Kontakt gekommen waren, $39-40^{\circ} \mathrm{C}$ Fieber. Es zeigten sich grippeähnliche Symptome wie Husten, Schnupfen, Gelenkschmerzen und große Müdigkeit. Die ,Erkrankung“" dauert fast eine Woche und wiederholt sich, sobald die Personen erneut mit den Sporen in Berührung kommen. Der Genuß von rohen Pilzen und gekochten Fruchtkörpern ist wirkungslos. Diese , ,Allergie “ wird nur von den tiber die Atemwege aufgenommenen Sporen ausgelöst. Immunologische Untersuchungen wurden bei Pleurotus florida durchgeführt [2].

Bei wiederholtem Kontakt mit den Sporen ändern sich die Symptome der Erkrankung. Fieber von $39-40^{\circ} \mathrm{C}$ wurde nur während der ersten Stunden beobachtet. Danach setzten starke Schweißausbrüche und Ubelkeit ein. Am nächsten Tag hat der Erkrankte Schwierigkeiten beim Ein- und Ausatmen.

Drei Tage nach dem Kontakt mit Pleurotus-Fruchtkörpern und Pleurotus-Sporen haben wir aus dem Sputum der betroffenen Person eine Pleurotus-Kultur isoliert, die einige Wochen später normale Primordien und Fruchtkörper auf der Agarkultur bildete. Die Sporen von Pleurotus ostreatus und $P$. florida keimen bei $15-37^{\circ} \mathrm{C}$. Bei Körpertemperatur $\left(36^{\circ} \mathrm{C}\right)$ ist die Sporenkeimung langsamer als bei der optimalen Tem- peratur von $25-30^{\circ} \mathrm{C}(2-3$ Tage). Das Myzel aus gekeimten Sporen wird durch Körpertemperaturen im Wachstum gehemmt.

In vitro haben wir die Beziehung zwischen der Gemischflora der Atemwege und Pleurotus-Sporen auf einem MalzextraktAgar untersucht. Die ,Sputumflora" entwickelte sich in 3 Tagen bei einer Temperatur von $30^{\circ} \mathrm{C} z \mathrm{u}$ vielen Kolonien mit einem Durchmesser von $2-5 \mathrm{~mm}$. In der gleichen Zeitspanne beobachteten wir auf anderen Schalen starke Sporenkeimung und Myzelwachstum von Pleurotus-Sporen. In der Gemischkultur aus Pleurotus-Sporen und Sputumflora zeigten die Pleurotus-Sporen, die in der gleichen Zeit wie die Kontrolle (Sporen ohne Sputum) ausgekeimt waren, ein schnelleres und kräftigeres Wachstum als die Kontrolle, und in kurzer Zeit war die Sputumflora vom Pleurotus-Myzel überwuchert. Die Stimulation der Sporenkeimung durch andere Mikroorganismen wurde schon mehrmals beschrieben.

Man kann annehmen, daß die Pleurotus-Sporen in den Atemwegen keimen können und daß dabei entstehende Stoffwechselprodukte die allergischen Erscheinungen verursachen.

\section{Eingegangen am 17. Juli 1974}

1. Zadražil, F.: Champignon 13, 143 (1973)

2. Schulz, K. H., Felten, G., Hausen, B. M. : Lancet 1974-I, 29 